\title{
ESTUDO DA DISSOLUÇÃO DE PRECIPITADOS NO REAQUECIMENTO DE PLACAS DE AÇOS MICROLIGADOS ATRAVÉS DA SIMULAÇÃO COMPUTACIONAL*
}

\author{
Elenice Cavichioli Borba ${ }^{1}$ \\ Cynthia Serra Batista Castro ${ }^{2}$ \\ Diana Maria Perez Escobar² \\ Fabio Dian Murari ${ }^{3}$ \\ Ed Juarez Mendes Taiss ${ }^{4}$ \\ André Luiz Vasconcellos da Costa e Silva ${ }^{5}$ \\ Margareth Spangler Andrade
}

\section{Resumo}

A dissolução de precipitados ricos em $\mathrm{Nb}$ durante o reaquecimento de placas é uma das etapas mais importantes no processamento dos aços microligados. $O$ conhecimento do teor de nióbio em solução ao fim dessa etapa é essencial no projeto termomecânico do aço. Neste estudo, aplicou-se a termodinâmica computacional para avaliar os efeitos do ciclo de reaquecimento de placas sobre o teor de nióbio dissolvido na austenita. Os resultados mostraram que, para determinado ciclo, há um limite máximo de tamanho de precipitado que pode ser dissolvido e que a homogeneidade da distribuição do nióbio em solução na austenita é dependente do ciclo empregado. Os resultados indicam que é possível aplicar ferramentas de termodinâmica computacional para otimizar os ciclos de processamento dos aços microligados.

Palavras-chave: Nióbio; Aço microligado; Dissolução de precipitados; DICTRA.

\section{A STUDY OF THE DISSOLUTION OF PRECIPITATES DURING MICROALLOYED STEELS REHEATING USING COMPUTATIONAL THERMODYNAMICS}

\section{Abstract}

Dissolving the $\mathrm{Nb}$ rich precipitates during plate reheating is one of the most important steps in the processing of microalloyed steels. The knowledge of the amount of $\mathrm{Nb}$ in solution at the end of reheating is essential to properly design the steel thermomechanical treatment. In this work, computational thermodynamics has been used to evaluate the effects of the reheating cycle on the dissolved $\mathrm{Nb}$ content of austenite. The results indicate that for a given cycle there is a maximum size of precipitate that can be dissolved and that austenite homogeneity heavily depends on the cycle parameters. The results indicate that computational thermodynamics tools can be profitably used to optimize the processing cycles of microalloyed steels.

Keywords: Niobium; Microalloyed steels; Dissolution of precipitates; DICTRA.

1 Física, D Sc., Pesquisadora, Instituto SENAl em Metalurgia e Ligas Especiais, Centro de Inovação e Tecnologia SENAI FIEMG - Campus CETEC, BH, MG, Brasil

2 Eng. Metalúrgica, D. Sc., Pesquisadora, Instituto SENAI em Metalurgia e Ligas Especiais, Centro de Inovação e Tecnologia SENAI FIEMG - Campus CETEC, BH, MG, Brasil

3 Eng. Metalúrgico, D. Sc., Pesquisador Especialista, USIMINAS, Ipatinga, MG, Brasil.

4 Eng. Metalúrgico, M. Sc., Consultor, CBMM - Companhia Brasileira de Metalurgia e Mineração, Araxá, MG, Brasil.

5 Eng. Metalúrgico, Ph.D, Prof. Titular, EEIMVR, UFF, Volta Redonda, RJ, Brasil.

6 Física, D. Sc., Diretora, Instituto SENAI em Metalurgia e Ligas Especiais, Centro de Inovação e Tecnologia SENAI FIEMG - Campus CETEC, BH, MG, Brasill 


\section{INTRODUÇÃO}

A dissolução de precipitados ricos em $\mathrm{Nb}$ durante o reaquecimento de placas é uma das etapas mais importantes no processamento dos aços microligados. $O$ conhecimento da quantidade de nióbio em solução ao fim dessa etapa é essencial no projeto do processamento termomecânico do aço. Em geral, o objetivo, no reaquecimento, é a dissolução da maior quantidade possível de precipitados ricos em $\mathrm{Nb}$, de modo a obter uma matriz austenítica rica em nióbio homogeneamente distribuído. Durante o trabalho a quente, o nióbio em solução retarda a recristalização da austenita e a precipitação de finos carbonitretos de nióbio permite um excelente controle do tamanho de grão austenítico [1,2]. Dependendo do processamento escolhido, é possível obter uma austenita encruada e de grãos alongados ("pancaking"), a qual possibilita atingir excelentes combinações de resistência e tenacidade no produto final. Entretanto, o conhecimento preciso da precipitação de carbonitretos, desde a solidificação até o esfriamento das placas e sua redissolução no forno de reaquecimento é ainda tema de importantes discussões e investigações. Estes trabalhos vêm sendo realizados desde a década de 1960 [3] até os dias de hoje [1,4-8]. Inicialmente, o foco foi na compreensão da solubilidade dos carbonitretos, uma vez que existe significante miscibilidade entre os carbonitretos cúbicos de $\mathrm{Nb}$, Ti e V $[9,10]$. Posteriormente, modelos semi-empíricos foram estabelecidos para a cinética de precipitação e dissolução destes carbonitretos. Alguns destes modelos obtiveram relativo sucesso, especialmente dentro das condições em que foram desenvolvidos. Entretanto, a capacidade de prever o comportamento de novas composições empregando estes modelos ainda é bastante limitada. Um dos problemas que dificultam as previsões da dissolução é o fato de que parte dos carbonitretos precipita em altas temperaturas durante a solidificação [11], o que leva à fixação de parte do nióbio nestes precipitados, inviabilizando sua dissolução na austenita durante o reaquecimento [12]. Além disso, as transformações que ocorrem no estado sólido são complexas, pois nem o reaquecimento da placa, nem, evidentemente, a laminação a quente, se passam de forma isotérmica. Da mesma forma, as composições dos carbonitretos em equilíbrio termodinâmico com a austenita variam em ampla faixa [13], levando à formação de carbonitretos de diferentes composições e morfologias que, naturalmente, se dissolvem de formas diversas a diferentes temperaturas, conforme demonstrado por Ruiz-Aparicio [14]. O reaquecimento, tema focal deste trabalho, é normalmente contínuo. Muitos estudos cinéticos empregam como premissa tratamentos isotérmicos. Deve se esperar que o ciclo de aquecimento e as diversas composições dos carbonitretos tenham grande importância no processo de dissolução e premissas simplificadoras como tratamento isotérmico e carbonitreto de composição "simples" possam induzir a resultados pouco confiáveis.

Neste estudo, portanto, aplicou-se a termodinâmica computacional para avaliar os efeitos do ciclo de reaquecimento de placas e da composição realmente esperada dos carbonitretos ricos em $\mathrm{Nb}$ sobre o teor de nióbio dissolvido na austenita em duas composições de aços microligados.

\section{MATERIAIS E MÉTODOS}

Nas simulações utilizaram-se os softwares Thermo-Calc para os cálculos de equilíbrio e DICTRA para os cálculos de difusão, ambos na versão 2015b. Foram empregados os bancos de dados termodinâmicos TCFE7 e de mobilidades MOBFE2 [15]. A dissolução do carbonitreto foi modelada assumindo uma célula esférica de austenita cercando um precipitado de carbonitreto, também esférico. $\mathrm{Na}$ 
simulação no DICTRA, os parâmetros de entrada foram o valor do raio do precipitado e da matriz austenítica e a composição química das fases calculadas no Thermo-Calc, partindo da composição química média simplificada para o sistema quinário $\mathrm{Fe}-\mathrm{C}-\mathrm{N}-\mathrm{Nb}-\mathrm{Ti}$, Tabela 1. Os raios médios das partículas foram obtidos a partir de medidas da distribuição dos diâmetros dos carbonitretos em amostras na condição como lingotada, na posição a $1 / 4$ da espessura da placa. As medidas foram realizadas por Microscopia Eletrônica de Varredura (MEV), utilizando-se o software Aztec. Os tamanhos de precipitados selecionados foram de $100 \mathrm{~nm}$, que na condição como lingotada, representavam a maior frequência na distribuição em ambos os aços, 9192 e 7895, e o de 280 nm em menor frequência na distribuição do aço 7895 . O diâmetro da célula de austenita foi calculado de modo a compatibilizar a fração volumétrica das duas fases com o diâmetro escolhido para o precipitado. $\mathrm{Na}$ simulação, a temperatura variou de $900^{\circ} \mathrm{C}$ até a temperatura de encharque de $1150^{\circ} \mathrm{C}$ no aço 9192 e de $1180^{\circ} \mathrm{C}$ no aço 7895 . A taxa de aquecimento foi de $0,14^{\circ} \mathrm{C} / \mathrm{s}$. Os tempos de encharque foram de 15,30 e $50 \mathrm{~min}$, indicados como $\mathrm{t} 15, \mathrm{t} 30$ e t50, respectivamente. O tempo de início do patamar de encharque foi indicado como to. O tempo de inicio do ciclo foi considerado como zero. Para o aço 9192, avaliou-se, também, o efeito do aumento da temperatura de encharque na faixa de $1180^{\circ} \mathrm{C}$ a $1280^{\circ} \mathrm{C}$, e da redução da taxa de aquecimento para $0,042^{\circ} \mathrm{C} / \mathrm{s}$. Para ilustrar a dificuldade da dissolução de um precipitado de maior diâmetro, também foram realizadas simulações utilizando-se o tamanho de precipitado de $500 \mathrm{~nm}$ para o aço 9192

Tabela 1. Composição química dos elementos nos aços, \% em massa.

\begin{tabular}{cccccc}
\hline Aço & $\mathbf{C}$ & $\mathbf{N}$ & $\mathbf{N b}$ & $\mathbf{T i}$ & $\mathbf{T i} / \mathbf{N}$ \\
\hline 9192 & 0,087 & 0,0035 & 0,019 & 0,022 & 6,3 \\
\hline 7895 & 0,074 & 0,0038 & 0,046 & 0,016 & 4,2 \\
\hline
\end{tabular}

\section{RESULTADOS E DISCUSSÃO}

A Figura 1 apresenta a distribuição de tamanho dos precipitados nos dois aços na condição como lingotada e após o tratamento até o tempo t50. Para o aço 9192 é possível observar um deslocamento da distribuição para menores tamanhos com o tratamento até o tempo t50. No aço 7895 o número de precipitados diminui mas a distribuição não é alterada significativamente.
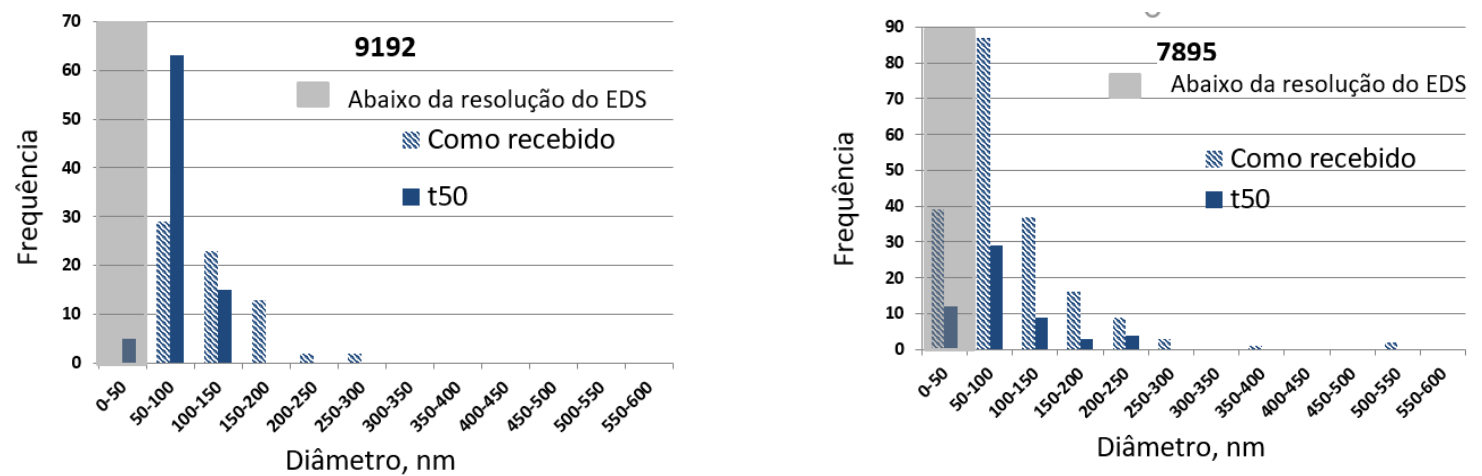

Figura 1. Distribuição de tamanhos de precipitados na região a $1 / 4$ da espessura das placas dos aços 9192 e 7895 nas condições como recebida e após tratamento até t50. A frequência no eixo y do gráfico é o número de precipitados por unidade de área.

A Figura 2 apresenta as fases em equilíbrio em função da temperatura, para os dois aços. É evidente que, no resfriamento, ocorre inicialmente a precipitação de um 
carbonitreto rico em $\mathrm{Ti}$ e $\mathrm{N}$ (identificado como $(\mathrm{Ti}, \mathrm{Nb})(\mathrm{C}, \mathrm{N})$ ) e, a temperaturas próximas de $1100^{\circ} \mathrm{C}$, ocorre a precipitação do carbonitreto rico em $\mathrm{Nb}$ e C (identificado como $(\mathrm{Nb}, \mathrm{Ti})(\mathrm{C}, \mathrm{N})$ ). A definição da temperatura de encharque para o reaquecimento foi feita considerando a temperatura de dissolução deste carbonitreto rico em $\mathrm{Nb}$ e $\mathrm{C}$. Observa-se também que a proporção relativa dos dois tipos de carbonitretos é significativamente diferente nos dois aços.

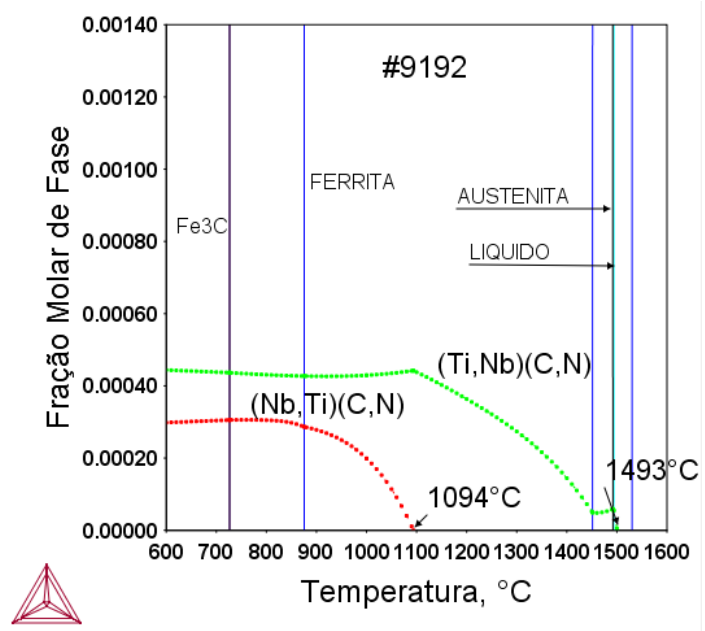

(a)

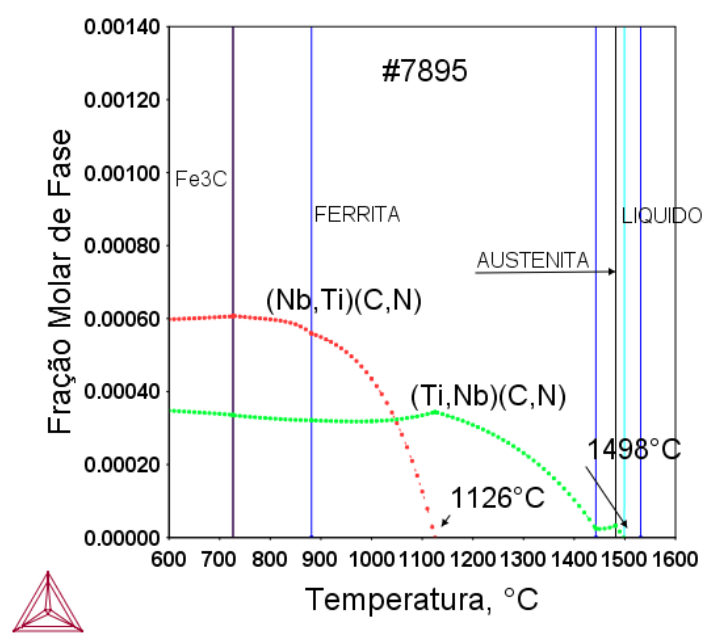

(b)

Figura 2. Fração molar de fases em equilíbrio calculada em função da temperatura nos aços (a) 9192 e (b) 7895 .

A simulação de dissolução, Figura 3, indica que a dissolução total dos precipitados ricos em nióbio com tamanho de 100nm (e menores, naturalmente) ocorre para os dois aços, próximo ao final da rampa de aquecimento (to). Para os carbonitretos ricos em nióbio na faixa de 280nm - 500nm de diâmetro, a dissolução é parcial até tempos superiores a t50.

Para o aço 9192, na condição como lingotado, é provável que tenha ocorrido formação significativa de precipitados ricos em nióbio nucleados sobre os primeiros precipitados formados no resfriamento, ricos em titânio e nitrogênio, como relatado por [14]. A elevada frequência de partículas na faixa de $50 \mathrm{~nm}-100 \mathrm{~nm}$ neste aço após o tratamento t50, Figura 1(a), deve estar associada à dissolução destes precipitados ricos em nióbio nucleados sobre os carbonitretos ricos em titânio, fenômeno relatado anteriormente $[15,16]$. Após o tratamento até t50, com a dissolução dos precipitados ricos em nióbio, os substratos estáveis do precipitado rico em titânio, que se situam nesta faixa de tamanho, têm contribuição importante na distribuição de partículas.

Por outro lado, no aço 7895, a frequência de partículas com tamanho na faixa de $50 \mathrm{~nm}-100 \mathrm{~nm}$ após o tratamento até t50 diminui drasticamente (cerca de $60 \%$ ) em relação à condição como recebida, Figura 1(b). Isto pode estar associado ao maior teor do nióbio e à maior relação $\mathrm{Nb} / \mathrm{Ti}$ nesta liga. Como visto na Figura 2, a relação entre as frações de precipitados ricos em nióbio e ricos em titânio neste aço, é muito superior à do aço 9192. Adicionalmente, a simulação da dissolução no aço 7895, Figura 3 (b), indica a dissolução total das partículas até $280 \mathrm{~nm}$ em tempos até t30, uma diferença significativa em relação ao comportamento do aço 9192.

Os resultados da Figura 3(c) mostram o efeito do aumento da temperatura de encharque na cinética de dissolução dos precipitados maiores, com diâmetro de 500nm. É possível observar que a dissolução total de partículas deste tamanho a $1200^{\circ} \mathrm{C}$ ocorre a partir de t50. O tempo da dissolução completa diminui com a 
elevação da temperatura, como esperado. Para temperatura de $1280^{\circ} \mathrm{C}$, a dissolução completa ocorre ainda na rampa de aquecimento.

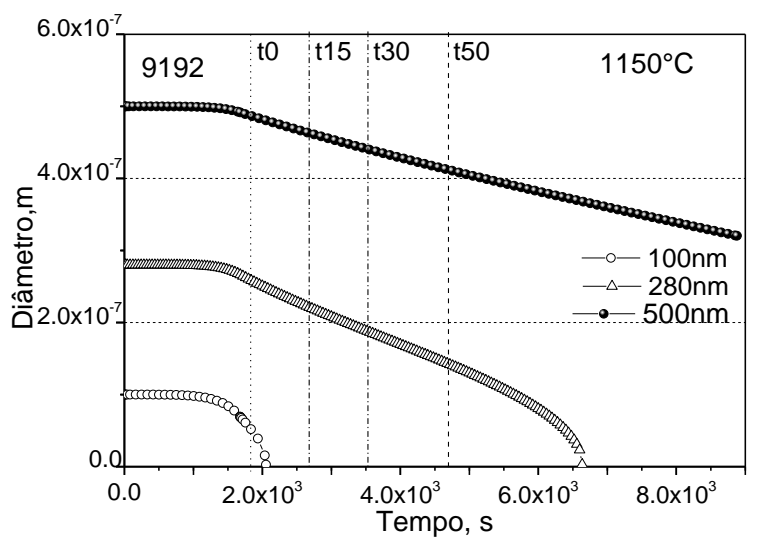

(a)

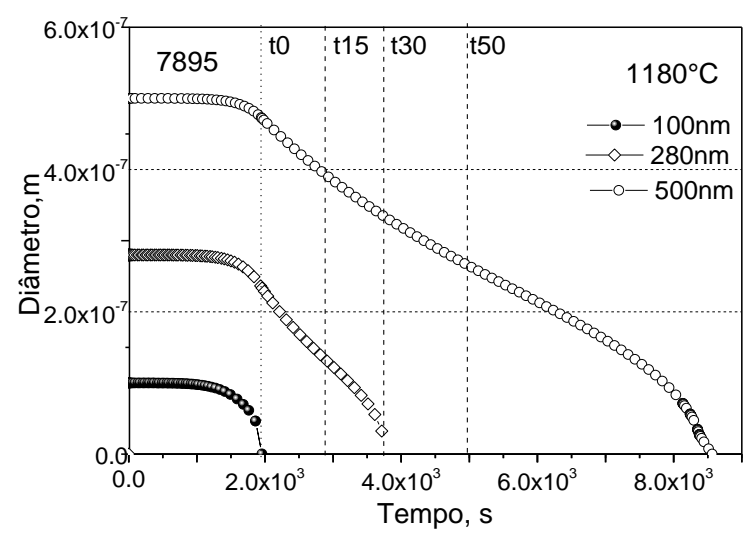

(b)

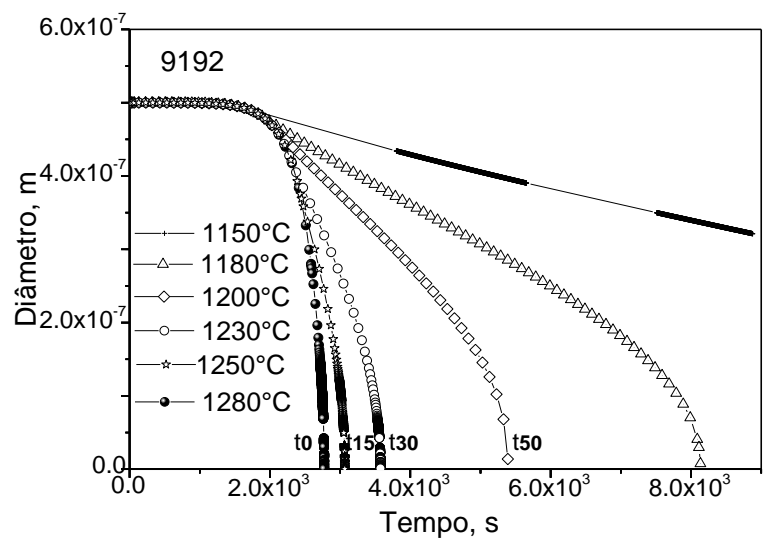

(c)

Figura 3. Simulação de dissolução de carbonitretos ricos em Nb e C, em função do ciclo de reaquecimento simulado para os aços 9192 (Figuras (a) e (c)) e 7895 (Figura (b)). Taxa de aquecimento $0,14^{\circ} \mathrm{C} / \mathrm{s}$. Os resultados são apresentados como diâmetro da partícula em função do tempo ao longo do ciclo de reaquecimento da placa.

\subsection{Nióbio solubilizado na austenita em função do tempo de dissolução}

A simulação da dissolução por difusão também fornece o teor de nióbio dissolvido na austenita. As Figuras 4(a) e (b) mostram o teor de nióbio na austenita durante a dissolução de precipitados de diferentes tamanhos, nos dois aços. É importante notar que, na simulação, não se considerou a formação de precipitados grosseiros na solidificação [11], que afetariam o teor total de nióbio disponível em partículas desta faixa de tamanho. Na parte superior do gráfico a linha horizontal pontilhada indica o teor de nióbio médio na liga e as linhas verticais tracejadas os tempos de rampa (aquecimento) e encharque. Como esperado, a rápida dissolução completa dos precipitados de diâmetro de 100nm faz com que o teor máximo de nióbio em solução na austenita seja atingido em tempos curtos. A Figura 4 (c) mostra o efeito do aumento da temperatura de encharque na contribuição dos precipitados de 500nm para o teor de nióbio em solução na matriz austenítica. 


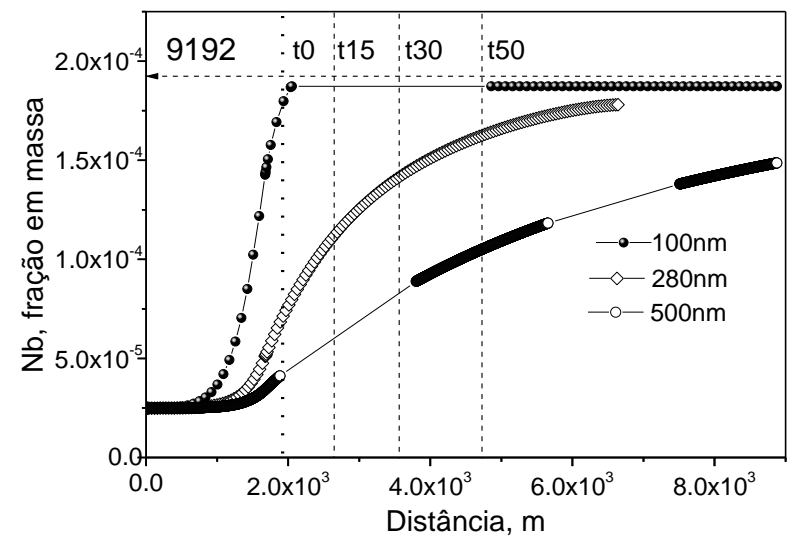

(a)

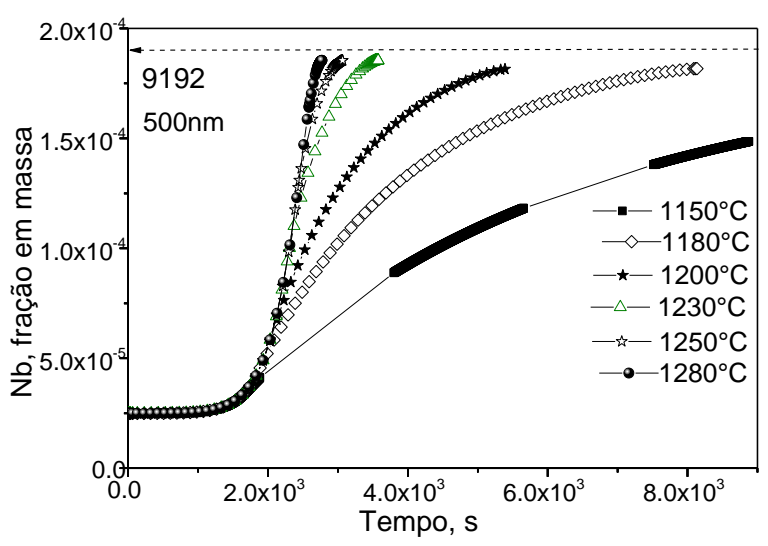

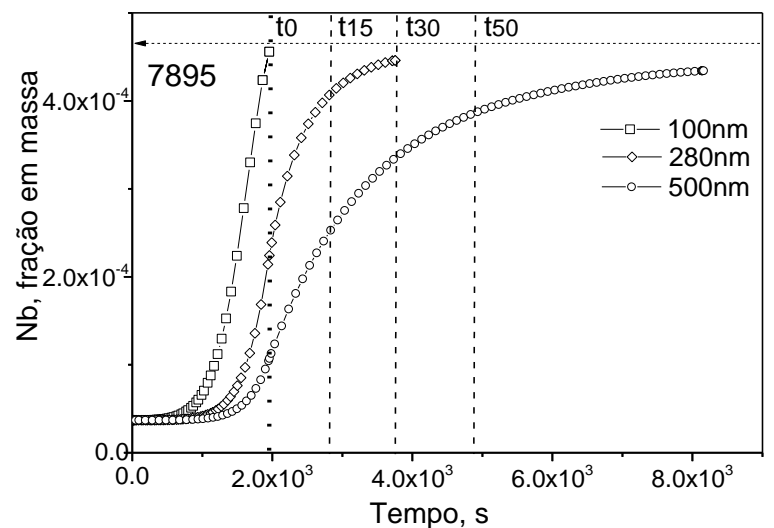

(b)

(c)

Figura 4. Fração de nióbio em função do tempo de simulação solubilizado na austenita com taxa de aquecimento de $0,14^{\circ} \mathrm{C} / \mathrm{s}$. (a) e (c) aço 9192 . (b) aço 7895 .

A simulação de difusão permite também avaliar a homogeneidade da austenita após a dissolução dos carbonitretos. A Figura 5 apresenta os perfis de nióbio, na austenita, a partir da posição final da interface carbonitreto-austenita (após a completa dissolução do carbonitreto) para dois tamanhos de partículas e diferentes tempos de tratamento. Os resultados indicam que o tempo para dissolver 0 precipitado não é suficiente para homogeneizar a austenita, por difusão. É evidente que a homogeneização é mais rápida após a dissolução dos precipitados de menor diâmetro (100nm). 


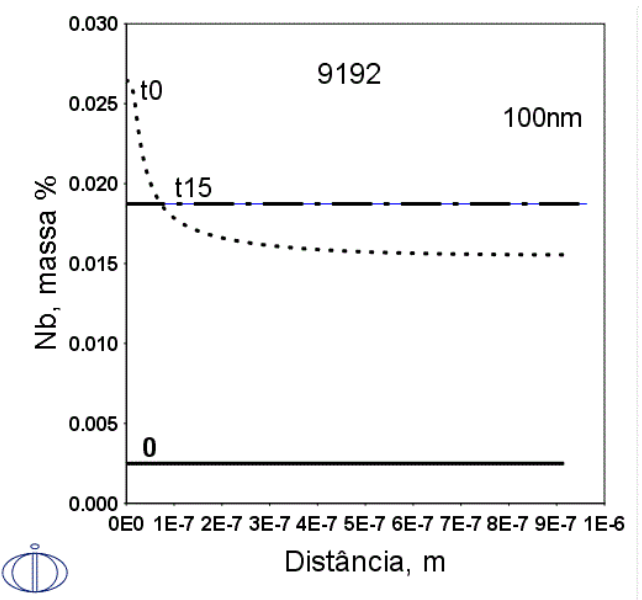

(a)

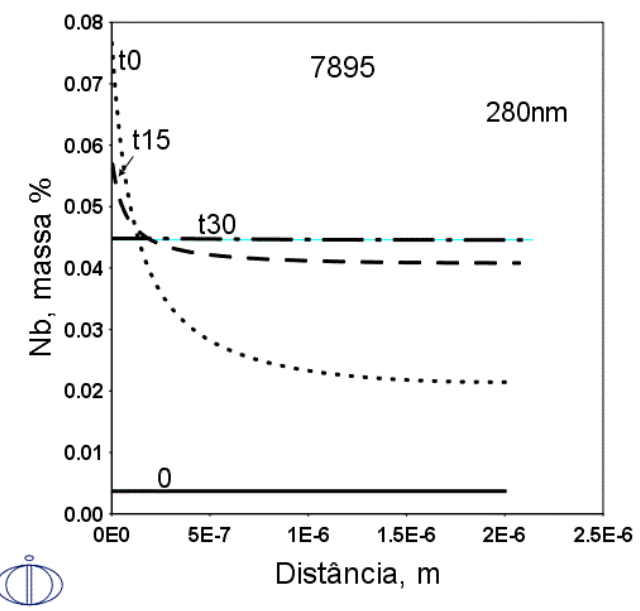

(b)

Figura 5. Perfil de concentração de nióbio na matriz austenítica antes da dissolução (linha horizontal identificada como 0) e nos tempos to, t15 e t3o para precipitados de diâmetro 100nm - aço 9192, (a), e $280 \mathrm{~nm}$ - aço 7895, (b). A coordenada $x=0$ corresponde à posição final da interface entre 0 carbonitreto e a matriz.

\subsection{Efeito da taxa de aquecimento na dissolução de precipitados}

$O$ efeito da taxa de aquecimento na dissolução de precipitados ricos em nióbio de $280 \mathrm{~nm}$ é apresentada na Figura 6 (a). O aquecimento a $0,042^{\circ} \mathrm{C} / \mathrm{s}$ leva a um tempo mais longo na dissolução do precipitado de $(\mathrm{Nb}, \mathrm{Ti})(\mathrm{C}, \mathrm{N})$ comparado à taxa de $0,14^{\circ} \mathrm{C} / \mathrm{s}$. O aquecimento mais lento leva à necessidade de maior tempo de tratamento para a dissolução das partículas, já que temperaturas elevadas precisam ser atingidas para que a cinética de dissolução seja favorecida. 


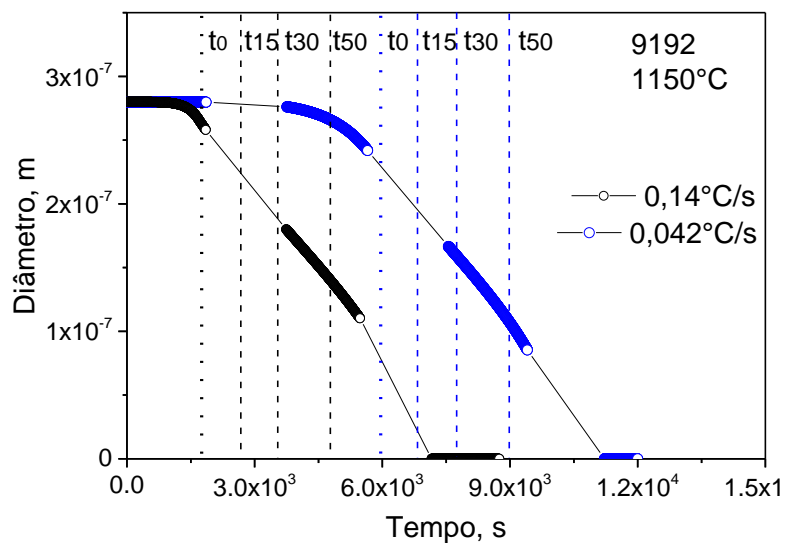

(a)

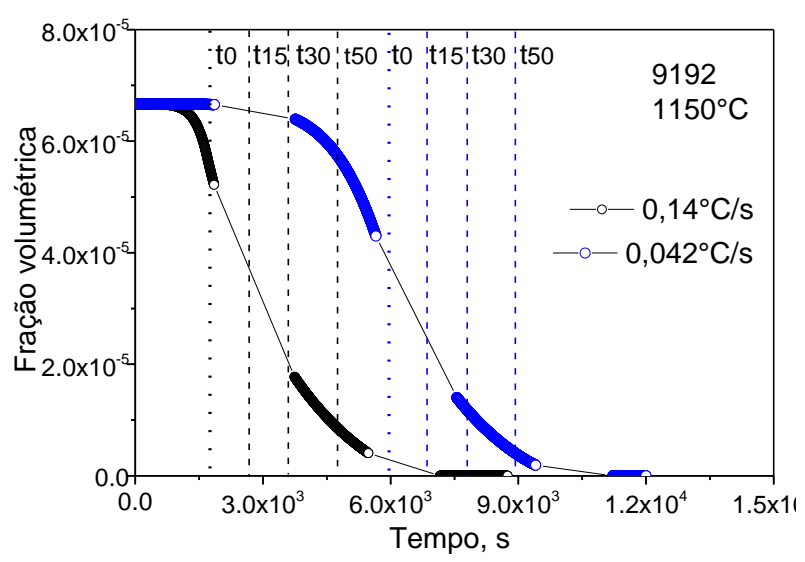

(b)

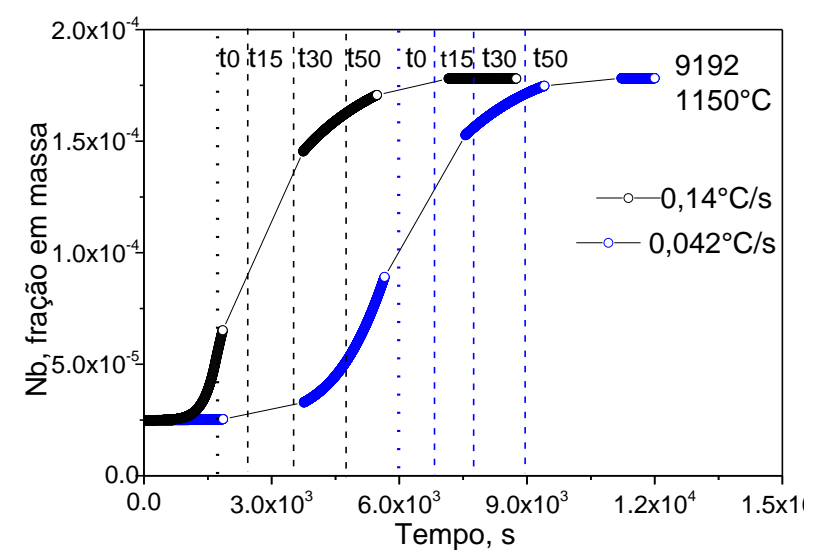

(c)

Figura 6. Efeito da taxa de aquecimento na cinética de dissolução de partícula de carbonitreto rico em nióbio de $280 \mathrm{~nm}$ para o aço 9192.

O aquecimento lento até a mesma temperatura também retarda a homogeneização do nióbio na austenita, como mostra a Figura 7. Para as partículas de $280 \mathrm{~nm} 0$ tempo necessário para homogeneizar o nióbio ocorre em tempos mais longos. 0 mesmo ocorre, evidentemente, para o precipitado de $100 \mathrm{~nm}$, ver Figura 5(a).

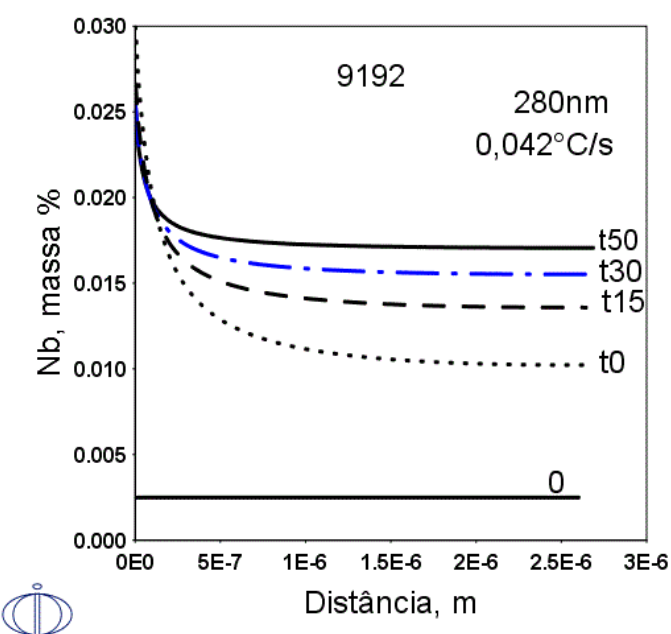

(a)

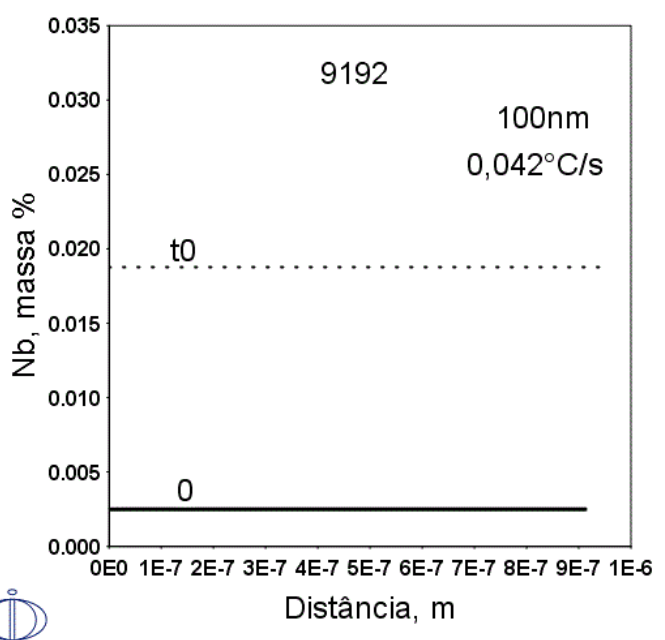

(b)

Figura 7. Distribuição de nióbio na austenita, aço 9192, a partir da completa dissolução do carbonitreto rico em nióbio para diferentes tempos de patamar e tamanhos de partícula (a) $280 \mathrm{~nm}$ e (b) $100 \mathrm{~nm}$. Taxa de aquecimento de $0,042^{\circ} \mathrm{C} / \mathrm{s}$. 


\section{CONCLUSÃO}

O modelamento termodinâmico e cinético da formação e dissolução dos carbonitretos ricos em nióbio permite avaliar o efeito da composição química do aço e do ciclo térmico de reaquecimento de placas de modo a otimizar o aproveitamento do nióbio na laminação a quente, maximizando a sua presença em solução no início do processo. No caso dos aços e ciclo de aquecimento estudado, por exemplo, observou-se que precipitados com diâmetro médio igual ou menor a $100 \mathrm{~nm}$ dissolvem completamente durante o aquecimento seguido de encharque com tempo inferior $15 \mathrm{~min}$, resultando em uma austenita homogênea. Taxas de aquecimento mais baixas demonstraram não contribuir para a dissolução. Assim, a aplicação do modelamento em questão é extremamente útil no projeto de ligas e no projeto de seu processamento, pois vários ciclos térmicos podem ser comparados e várias composições visadas podem ser avaliadas.

\section{Agradecimentos}

Os autores agradecem à Companhia Brasileira de Mineração e Metalurgia-CBMM e à USIMINAS pelo apoio técnico e fornecimento de amostras. M.S.A. e A.C.S. agradecem ao CNPq, FAPEMIG e CAPES pelas bolsas e apoios concedidos.

\section{REFERÊNCIAS}

1 Gladman T. The physical Metallurgy of microalloyed steels. London: Institute of Materials, Maney Publishing; 2002.

2 Charleux M., Poole WJ., Militzer M., Deschamps A. Precipitation behavior and its effect on strengthening of an HSLA-Nb/Ti steel. Metall. and Mater. Trans. A. 2000; 32A: 16351647.

3 Dutta B., Palmiere EJ., Sellars CM. Modeling the kinetics of strain induced precipitation in Nb microalloyed steels. Acta Mater. 2001; 49: 785-794.

4 Roy S., Patra S., Neogy S., Laik A., Choudhary SK., Chakrabarti D. Prediction of inhomogeneous distribution of microalloy precipitates in continuous high-strength, lowalloy steel slab. Metall. Mater. Trans. A. 2012; 43A: 1845-1860.

5 Perrard F., Deschamps A., Bley F., Donnadieu P., Maugis P. A Small-angle neutron scattering study precipitation kinetics in the $\alpha-\mathrm{Fe}-\mathrm{Nb}-\mathrm{C}$ system. Appl. Cryst. 2006; 39, 473-482.

6 Bhadeshia HKDH. Local brittle zones and the role of niobium. Mater Sci. Forum. 2014; 783-786: 2129-2135.

7 Zheng S., Davis C., Strangwood M. Elemental segregation and subsequent precipitation during solidification of continuous cast $\mathrm{Nb}-\mathrm{V}$-Ti high-strength low-alloy steels. Mater. Charac.2014: 95: 94-104.

8 Perez M., Courtois E., Acevedo D., Epicier T., Maugis P. Precipitation of niobium carbonitrides in ferrite: chemical composition measurements and thermodynamic modelling. Philos. Mag. Letters. 2014; 87(9): 645-656.

9 Balasubramanian K., Kirkaldy JS. Experimental investigation of the thermodynamics of Fe-Nb-N austenite and nonstoichiometric Niobium Nitride (1373-1673K). Canadian Metallurgical Quarterly. 1989;28(4):301-15.

10 Strid J., Easterling KE. On the chemistry and stability of complex carbides and nitrides in microalloyed steels. Acta Metallurgica. 1985 Nov 1;33(11):2057-74.

11 Escobar, DP, Castro CSB, Borba EC, Camei K., Taiss E., Costa e Silva, A., Andrade MS. Efeito do caminho de solidificação sobre a microestrutura de solidificação e a precipitação de $\mathrm{Ti}, \mathrm{Nb}(\mathrm{C}, \mathrm{N})$ em um aço baixo $\mathrm{Mn}$ alto $\mathrm{Nb}$. (Trabalho a ser publicado no 72ํㅡㄹ Congresso Anual da ABM). 
12 Larzabal G., Garcia-Sesma L., Pereda B., Uranga P., Rebellato M., López B., Rodriguez-lbabe JM. Validation of an indirect technique to quantify the amount of niobium in solution prior to hot rolling In: Contributed Papers from Materials Science and Technology 2016 (MS\&T16). Salt Palace Convention Center, Salt Lake City, Utah USA; 2016, pp. 509-516.

13 Inoue K., Ishikawa N., Ohnuma I., Ohtani H., Ishida K. Calculation of Phase Equilibria between Austenite and (Nb, Ti, V) $(\mathrm{C}, \mathrm{N})$ in Microalloyed Steels. ISIJ International. 2001;41(2):175-82.

14 Ruiz-Aparicio A. Evolution of microstructure in $\mathrm{Nb}$-bearing microalloyed steels produced by the compact strip production process, M.Sc. Thesis, University of Pittsburgh; 2004.

15 Andersson JO, Helander T., Höglund L., Shi P., Sundman B. Thermo-Calc \& DICTRA, computational tools for materials science. Calphad. 2002;26(2):273-312.

16 Kapoor M., O’Malley R., Thompson GB. Metall. Trans. A. 2016; 47: 1984-1995. 